\title{
Synthesis of Novel Isatin-Type 5'-(4-Alkyl/Aryl-1H-1,2,3-triazoles) via 1,3-Dipolar Cycloaddition Reactions
}

\author{
Bianca N. M. Silva, ${ }^{*, a}$ Bárbara V. Silva, ${ }^{a}$ Fernando C. Silva, ${ }^{b}$ Daniel T. G. Gonzaga, ${ }^{b}$ \\ Vitor F. Ferreira ${ }^{b}$ and Angelo C. Pinto ${ }^{a}$
}

\author{
anstituto de Química, Universidade Federal do Rio de Janeiro, 21949-900 Rio de Janeiro-RJ, Brazil \\ ${ }^{b}$ Instituto de Química, Universidade Federal Fluminense, 24020-141 Niterói-RJ, Brazil
}

\begin{abstract}
As isatinas e os 1H-1,2,3-triazóis são duas classes de compostos com grande destaque na síntese orgânica e na química medicinal uma vez que são núcleos heterociclos com elevada reatividade, que permitem a obtenção de diversos compostos com importantes propriedades biológicas. Neste artigo, a síntese de novos 5 -(4-alquil/aril-1H-1,2,3-triazóis)-isatina via reação de cicloadição 1,3-dipolar catalisada por ácido acético é descrita.
\end{abstract}

Isatin and 1H-1,2,3-triazoles are two classes of compounds with great prominence in organic synthesis and medicinal chemistry as they are heterocycle nuclei with a high reactivity allowing to obtain several compounds with important biological properties. Herein, the synthesis of novel 5'-(4-alquil/aril-1H-1,2,3-triazole)-isatin via reaction of 1,3-dipolar cycloaddition catalyzed by acetic acid is reported.

Keywords: isatin, 1H-1,2,3-triazoles, 1,3-dipolar cycloaddition reactions

\section{Introduction}

Isatin (2,3-dihydro-2,3-dioxo-1H-indole 1, Figure 1a) is a simple small molecule that is present in plants of the genus Isatis ${ }^{1}$ and in some animals like, such as Bufo frogs. ${ }^{2}$ This compound is also distributed in different regions of the brain and in various body fluids in humans. ${ }^{3-5}$ Its reactivity has been explored by several research groups due to its structure, which allows nucleophilic substitution reactions involving the aromatic ring, especially at positions 5 and $7 ; ;^{6}$ acylation $^{7}$ or alkylation ${ }^{8}$ at the $\mathrm{N}-\mathrm{H}$; and reduction ${ }^{9}$ or condensation ${ }^{10-12}$ at the amide [C-2] and ketone [C-3] carbonyls, which have distinct reactivities.

Isatin and its derivatives have been reported to exhibit a variety of biological properties, and are also frequently employed as raw materials to produce bioactive compounds. ${ }^{13}$ Isatin and its derivatives show sedativehypnotic, ${ }^{14}$ antitumor, ${ }^{15,16}$ antimicrobial, ${ }^{17}$ antibacterial, ${ }^{18}$ anticonvulsant, ${ }^{19}$ anticancer, ${ }^{20}$ and anti-HIV ${ }^{21}$ activities, among others.

Triazoles represent a class of five-membered heterocyclic compounds of great importance in the

*e-mail: biancanascimento@iq.ufrj.br preparation of new drugs with diverse biological activities because these compounds can have different structures with the same numbers of carbon and nitrogen atoms. $1 H-1,2,3-$ Triazoles (4, Figure 1b) are compounds of exclusively synthetic origin, ${ }^{22}$ and there are several methods available for the 1,4 regiospecific synthesis of $1 H-1,2,3$-triazoles. The 1,3-dipolar cycloaddition of organic azides (2) with terminal alkynes (3) catalyzed by $\mathrm{Cu}(\mathrm{I})$ is one of the most versatile of these methods. ${ }^{23}$

(a)

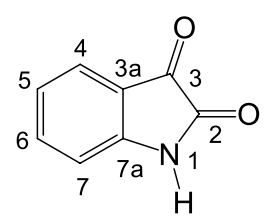

1

(b)

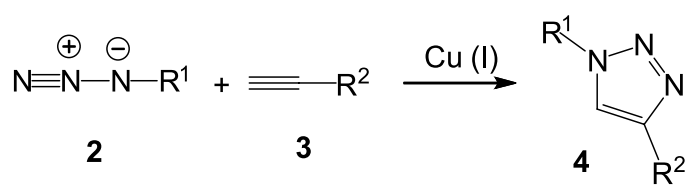

Figure 1. (a) Structure of isatin and (b) scheme for obtaining 1,2,3-triazoles (4) from organic azides (2) and terminal alkynes (3). 


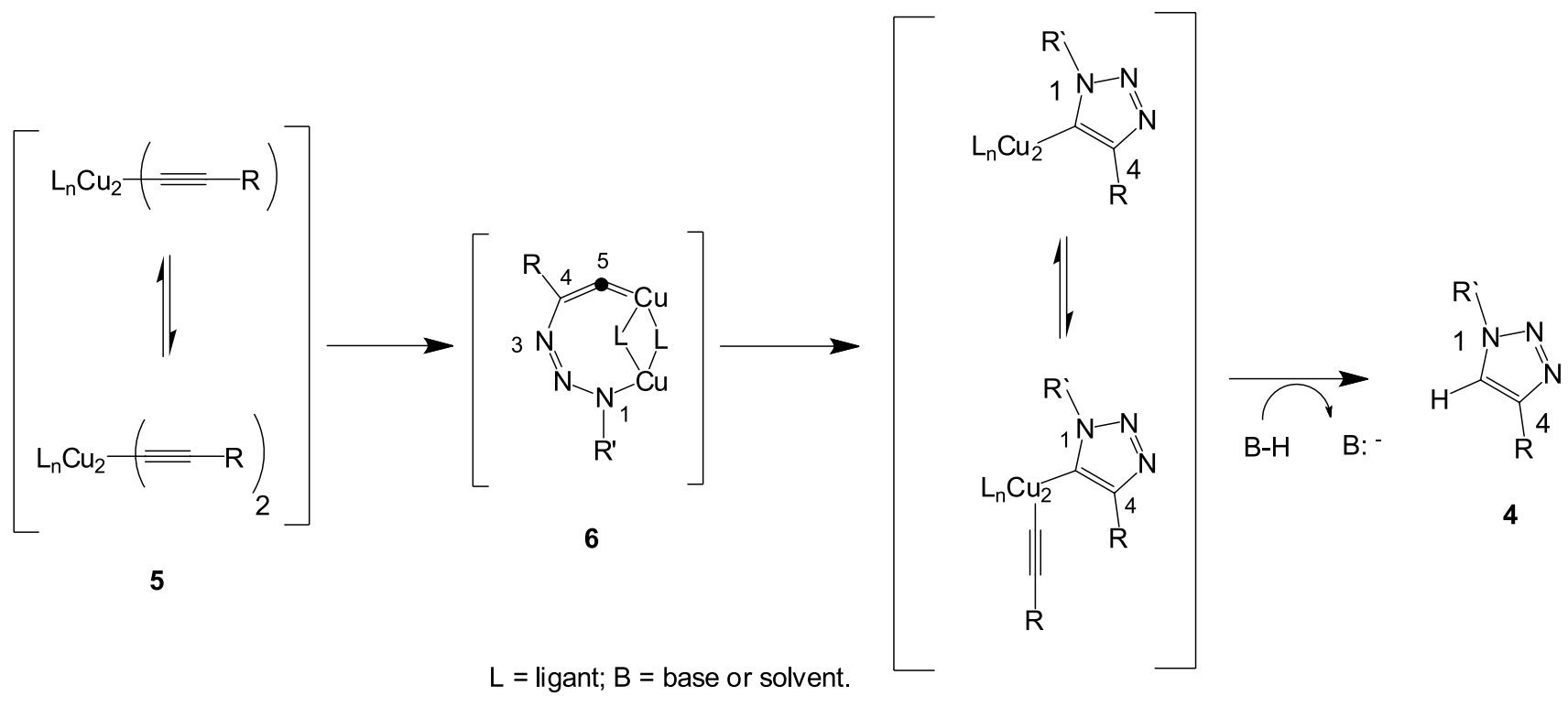

Figure 2. Simplified mechanism of the 1,3-dipolar cycloaddition that yield 1,4-disubstituted 1,2,3-triazoles (4).

Although the reaction mechanism is not yet completely understood, studies have indicated that the formation of copper acetylide (5) is followed by the generation of an unstable cyclic intermediate $(\mathbf{6})$ that undergoes protonolysis following successive steps, yielding 1,4-disubstituted 1,2,3-triazoles (4) (Figure 2). ${ }^{24-26}$

Currently, the most widespread reaction condition employed for the 1,4- regiospecific method is the use of an organic solvent, such as $t-\mathrm{BuOH}$ or $\mathrm{CH}_{2} \mathrm{Cl}_{2}$, water, $\mathrm{CuSO}_{4} .5 \mathrm{H}_{2} \mathrm{O}$ and sodium ascorbate. ${ }^{27,28}$

Hein and Folkin ${ }^{29}$ claim in their work that the presence of water in the reaction medium is essential to maintain copper acetylide (5) in its reactive state because the complexation of $\mathrm{Cu}(\mathrm{I})$ with the alkyne in an aqueous system decreases the pKa of hydrogen at 9.8 units, favoring its deprotonation. However, Shao et al..$^{30}$ observed that the use of protic solvents in presence of base ( $N, N$-diisopropylethylamine or triethylenediamine), which are used to reduce $\mathrm{Cu}$ (II) to $\mathrm{Cu}(\mathrm{I})$, promoted the formation of dimers as byproducts, such as diacetylenes, bis-triazoles and 5-hydroxytriazoles. Moreover, Straub and co-workers ${ }^{30}$ have described that acetic acid more efficiently promoted the breaking of the $\mathrm{C}-\mathrm{Cu}$ bond to give $\mathrm{C}-\mathrm{H}(\mathbf{4})$, leading to the desired product in a shorter time.

In 2010, Sun and $\mathrm{Wu}^{32}$ proposed the use of an azide:alkyne molar ratio of $1: 1$ based on the results obtained using infrared spectroscopy. This ratio differs from the ratios used in many other studies, which employed excess azide. It is noteworthy that the unreacted excess azide must be removed using a column, which requires additional time and solvent and decreases the reaction yield.
Triazoles have been attracting increasing attention from the scientific community because of the wide variety of pharmacological activities that this class exhibits. Although their 1,2,4-regioisomers are present in many drugs, 1,2,3-triazoles are of great interest due to their excellent synthetic accessibility. There are reports that the triazole ring acts as a bioisostere of the amide functional group but it is more stable because undergoes hydrolysis, oxidation or reduction. Furthermore, 1,2,3-triazoles have large dipole moments (ca. $5 \mathrm{D}$ ), and the nitrogens at positions 2 and 3 act as weak hydrogen bond acceptors..$^{33}$

The literature describes a series of biological properties $^{34}$ for 1,2,3-triazoles and their derivatives, such as antitubercular, ${ }^{35}$ fungicidal, ${ }^{36}$ anti-HSV, ${ }^{37}$ anti$\mathrm{HIV},{ }^{38}$ antitumor, ${ }^{39}$ anti-inflammatory ${ }^{40}$, tripanocidal, ${ }^{41}$ antimicrobial, ${ }^{42}$ antiplatelet ${ }^{43}$ and anticonvulsivant activities. $^{44}$

\section{Results and Discussion}

In this article, it is described the synthesis of novel isatin derivatives, 5'-(4-alkyl/aryl- $1 H$-1,2,3-triazoles) (11a-l), using 5-azido-spiro[1,3-dioxolane-2,3'-indol]-2' $\left(1^{\prime} H\right)$ one (10) in the presence of various alkynes under acidic conditions (Scheme 1). The products were characterized by infrared spectroscopy (IR), nuclear magnetic resonance (NMR) spectroscopy and electrospray mass spectrometry (ESI-MS).

Initially, 5-nitro-spiro[1,3-dioxolane-2,3'-indol]2'(1'H)-one (8) was prepared from 5-nitro-isatin (7), using ethylene glycol, $p$-toluenesulfonic acid and toluene in a $67 \%$ yield. Then, the nitro group was reduced by 

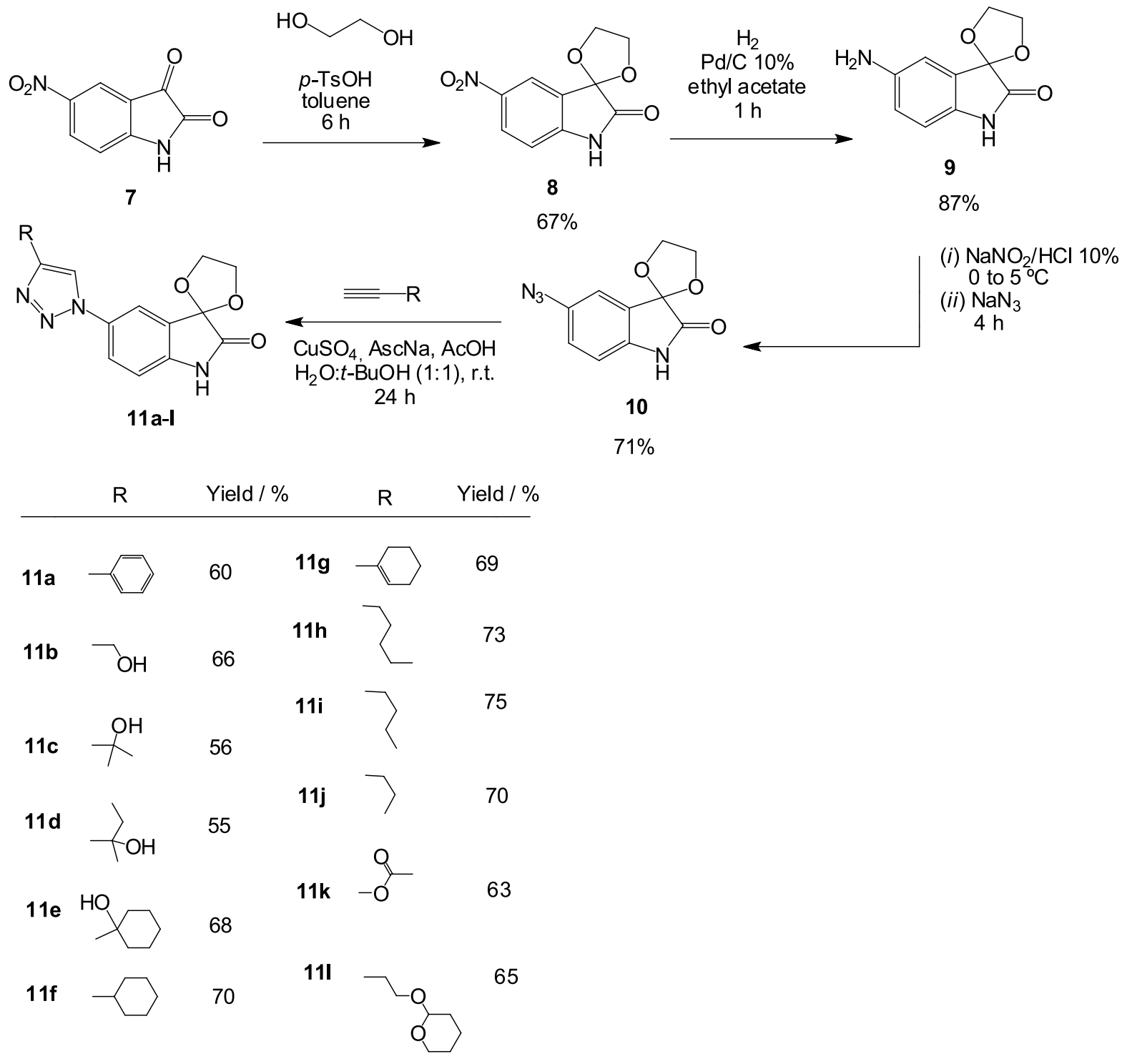

Scheme 1. Yields and reaction conditions for novel isatin-type 5 -(4-alkyl/aryl-1H-1,2,3-triazoles) (11a-l).

catalytic hydrogenation to give 5-amino isatin (9), in an $87 \%$ yield. In the next step, the azido group was obtained using a diazotization reaction with sodium nitrite in an acidic medium, with subsequent addition of sodium azide, producing $\mathbf{1 0}$ (Scheme 1).

Preliminary studies of the reaction of product $\mathbf{1 0}$ with terminal alkynes were performed using $\mathrm{CuSO}_{4} \cdot 5 \mathrm{H}_{2} \mathrm{O}$, sodium ascorbate and $\mathrm{CH}_{2} \mathrm{Cl}_{2}$ as the solvent. These reaction conditions furnished triazoles in yields below $30 \%$. Next, to improve the yields, the dichloromethane was replaced with a 1:1 mixture of tert-butanol, and $30 \mathrm{~mol} \%$ (based on 10) of acetic acid was added, leading to products 11a-11I in good yields (55-75\%).

As shown in Scheme 1, in all cases, the reactions were conducted over $24 \mathrm{~h}$, and the nature of the substituent did not have significant influence on the reactivity of the alkyne. Furthermore, although an acidic medium was used, the dehydration of alkynes having hydroxyl group was not observed (11b-11e).

The ${ }^{1} \mathrm{H}$ NMR spectra showed that the structures of the triazole compounds shared a common signal from the amide hydrogen, which appeared at $10.7 \mathrm{ppm}$, whereas the hydrogen attached to the triazole ring appeared in the range of 8.5 to $9.2 \mathrm{ppm}$. The hydrogens H-8 and H-9 appeared as a multiplet at 4.30 to $4.36 \mathrm{ppm}$ (see Supplementary Information section).

\section{Conclusion}

In summary, we described herein the synthesis, in good yields, of a series novel isatin-type 5'-(4-alkyl/aryl-1H1,2,3-triazoles) (11a-l) using the classical method for the 
preparation of 1,4-disubstituted 1,2,3-triazoles from organic azides and terminal alkynes. These novel isatin derivatives are promising candidates for the treatment of different illness, including cancer and neglected diseases, and these compounds have the ability to act on the central nervous system.

\section{Supplementary Information}

Supplementary information associated with this work contains NMR spectra $\left({ }^{1} \mathrm{H}\right.$ and $\left.{ }^{13} \mathrm{C}\right)$, infrared and the typical procedure for preparation of the compounds (Experimental section). These data are available free of charge at http://jbcs.sbq.org.br as a PDF file.

\section{Acknowledgment}

The authors thank the Brazilian agencies National Counsel for Technological and Scientific Development (CNPq) and State of Rio de Janeiro Research Foundation (FAPERJ).

\section{References}

1. Guo, Y.; Chen, F.; Zhongcaoyao 1986, 17, 8 (CA 104:213068f).

2. Wei, L.; Wang, Q.; Liu, X.; Yaowu Fenxi Zazhi 1982, 2, 288 (CA 98:95726b).

3. Ischia, M.; Palumbo, A.; Prota, G.; Tetrahedron 1988, 44, 6441.

4. Palumbo, A.; Ischia, M.; Misuraca, G.; Prota, G.; Biochim. Biophys. Acta 1989, 990, 297.

5. Halket, J. M.; Watkins, P. J.; Przyborowska, A.; Goodwin, B. L.; Clow, A.; Glover, V.; Sandler, M.; J. Chromatogr. 1991, 562, 279.

6. Silva, B. V.; Esteves, P. M.; Pinto, A. C.; J. Braz. Chem. Soc. 2011, 22, 257.

7. Boechat, N.; Kover, W. B.; Bastos, M. M.; Pinto, A. C.; Maciel, L. C.; Mayer, L. M. U.; Silva, F. S. Q.; Sá, P. M.; Mendonça, J. S.; Wardell, S. M. S. V.; Arruda, M. S. L.; J. Braz. Chem. Soc. 2008, 19, 445 .

8. Schmidt, M. S.; Perillo, I. A.; González, M.; Blanco, M. M.; Tetrahedron Lett. 2012, 53, 2514.

9. Garden, S. J.; Côrrea, M. B.; Pinto, A. C.; Tetrahedron Lett. 2003, 44, 7617.

10. Luppi, G.; Monari, M.; Corrêa, R. J.; Violante, F. A.; Pinto, A. C.; Kaptein, B.; Broxterman, Q. B.; Garden, S. J.; Tomasini, C.; Tetrahedron 2006, 62, 12017.

11. Silva, B. V.; Ribeiro, N. M.; Pinto, A. C.; Vargas, M. D.; Dias, L. C.; J. Braz. Chem. Soc. 2008, 19, 1244.

12. Silva, B. V.; Ribeiro, N. M.; Vargas, M. D.; Lanznaster, M.; Carneiro, J. W. M.; Krogh, R.; Andricopulo, A. D.; Dias, L. C.; Pinto, A. C.; Dalton Trans. 2010, 39, 7338.
13. da Silva, J. F. M.; Garden, S. J.; Pinto, A. C.; J. Braz. Chem. Soc. 2001, 12, 273.

14. Zudo, G.-S.; Pontes, L. B.; Gabriel, D.; Mendes, T. C. F.; Ribeiro, N. M. Pinto, A. C.; Trachez, M. M.; Sudo, R. T.; Pharmacol. Biochem. Behav. 2007, 86, 678.

15. Sun, S. Schiller, J. H.; Crit. Rev. Oncol. Hematol. 2007, 62, 93.

16. Vine, K. L.; Matesic, L.; Locke, J. M.; Ranson, M. Skropeta, D.; Anti-Cancer Agents Med. Chem. 2009, 9, 397.

17. Pandeya, S. N.; Siriram, D.; Nath, C.; De Clercq, E.; Il Farmaco 1999, 54, 624.

18. Sridhar, S. K.; Saravanan, M.; Ramesh, A.; Eur. J. Med. Chem. 2001, 36, 615.

19. Küçükgüzel, I.; Küçükgüzel, S. G.; Rollas, S.; Sanis, G. Ö; Özdemir, O.; Bayrak, I.; Altug, T.; Stables, J. P.; Il Farmaco 2004, 59, 893.

20. Singh, P.; Sharma, P.; Anand, A.; Bidi, P. M. S.; Kaur, T.; Saxena, A. K.; Kumar, V.; Eur. J. Med. Chem. 2012, 55, 455.

21. Pandeya, S. N.; Sriram, D.; Nath, G.; Declercg, E.; Eur. J. Pharm. Sci.1999, 9, 25.

22. Melo, J. O. F.; Donnici, C. L.; Augusti, R.; Ferreira, V. F.; Souza, M. C. B. V.; Ferreira, M. L. G.; Cunha, A. C.; Quim. Nova 2006, 29, 569 .

23. Tornøe, C. W.; Christensen, C.; Meldal, M.; J. Org. Chem. 2002, 67, 3057.

24. Rostovtsev, V. V.; Green, L. G.; Fokin, V. V.; Sharpless, K. B.; Angew. Chem., Int. Ed. 2002, 41, 2596.

25. Freitas, L. B. O.; Ruela, F. A.; Pereira, G. R.; Alves, R. B.; Freitas, R. P.; Quim. Nova 2011, 34, 1791.

26. Aragão-Leoneti, V.; Campo, V. L.; Gomes, A. S.; Field, R. A.; Carvalho, I.; Tetrahedron 2010, 66, 9475.

27. Rostovtsev, V. V.; Green, L. G.; Fokin, V. V.; Sharpless, K. B.; Angew. Chem., Int. Ed. 2002, 41, 2596.

28. Wu, P.; Fokin, V. V.; Aldrichimica Acta 2007, 40, 7.

29. Hein, J. E.; Fokin, V. V.; Chem. Soc. Rev. 2010, 39, 1302.

30. Shao, C.; Wang, X.; Zhang, Q.; Luo, S.; Zhao, J.; Hu, Y.; J. Org. Chem. 2011, 76, 6832.

31. Nolte, C.; Mayer, P.; Straub, B. F. Angew. Chem., Int. Ed. 2007, 46, 2101.

32. Sun, S.; Wu, P.; J. Phys. Chem. A. 2010, 114, 8331.

33. Agalave S. G.; Maujan S. R.; Pore V. S.; Chem. Asian J. 2011, 6, 2696.

34. Boechat, N.; Ferreira, V. F.; Ferreira, S. B.; Ferreira, M. L. G.; da Silva, F. C.; Bastos, M. M.; Costa, M. S.; Lourenço, M. C. S.; Pinto, A. C.; Krettli, A. U.; Aguiar, A. C.; Teixeira, B. M.; da Silva, N. V.; Martins, P. R. C.; Bezerra, F. A. F. M.; Camilo, A. L. S.; da Silva, G. P.; Costa, C. C. P.; J. Med. Chem. 2011, 54, 5988.

35. Radice, M.; Pieranto, P.; Plant Sci. 1991, 74, 81

36. Jordão, A. K.; Ferreira, V. F.; Souza, T. M. L.; Faria, G. G. S.; Machado, V.; Abrantes, J. L.; Souza, M. C. B. V.; Cunha, A. C.; Bioorg. Med. Chem. 2011, 19, 1860. 
37. Akselsen, Ø. W.; Odlo, K.; Cheng, J.-J.; Maccari, G.; Botta, M.; Hansen, T. V.; Bioorg. Med. Chem. 2012, 20, 234

38. da Silva, F. C.; de Souza, M. C. B. V.; Frugulhetti, I. I. P.; Castro, H. C.; Souza, S. L. O.; de Souza, T. M. L.; Rodrigues, D. Q.; Souza, A. M. T.; Abreu, P. A.; Passamani, F.; Rodrigues, C. R.; Ferreira, V. F.; Eur. J. Med. Chem. 2009, 44, 373.

39. Uzgören-Baran, A.; Tel, B. C.; Sarigöl, D.; Öztürk, E. I.; Kazkayasi, I.; Okay, G.; Ertan, M.; Tozkoparan, B.; Eur. J. Med. Chem. 2012, 57, 398

40. da Silva E. N. Jr; Guimarães T. T.; Menna-Barreto R. F. S.; Pinto, F. R. M. do C; de Simone C. A; Pessoa C.; Cavalcanti, B. C.; Sabino, J. R.; Andrade, C. K. Z.; Goulart, M.O.F.; de Castro, S. L., Pinto, A. V.; Bioorg. Med. Chem. 2010, 18, 3224.
41. Thomas, K. D.; Adhikari, A. V.; Shetty, N. S.; Eur. J. Med. Chem. 2010, 45, 3803.

42. Cunha, A. C.; Figueiredo, J. M.; Tributino, J.; Miranda, A. L.; Castro, H.C.; Zingali, R. B.; Fraga, C. A.; de Souza, M. C.; Ferreira, V. F.; Barreiro, E. J.; Bioorg. Med. Chem. 2003, 11, 2051.

43. Kelley, J. L.; Koble, C. S.; Davis, R. G.; McLean, E. W.; Soroko, F. E.; Cooper, B. R.; J. Med. Chem. 1995, 38, 4131.

44. Kadaba, P. K.; J. Med. Chem. 1998, 31, 196.

Submitted: December 2, 2012 Published online: February 7, 2013 